\title{
Inclusive classroom strategies for raising the achievement of students with dyslexia
}

New Zealand Journal of Teachers' Work, Volume 15, Issue 2, 100-104, 2018

\author{
ALENA STUART \\ ANNE YATES \\ Victoria University of Wellington
}

\section{INTRODUCTION}

The purpose of this research overview is to analyse literature on dyslexia and to identify and evaluate a range of inclusive classroom strategies which can influence the educational achievement of students with dyslexia. Tunmer and Greaney (2010) define dyslexia as "persistent learning difficulties" (p. 239) which present in "otherwise typically developing children, despite exposure to high quality, evidence-based literacy instruction and intervention" (p. 239). The difficulties arise due to a lack of phonemic awareness, key skills required to access literacy (2010). According to Mills (2018) there is no "quick fix or one prescribed intervention" (p. 38) to remediate dyslexia. This research overview provides an analysis of four studies followed by an evaluation of strategies suggested to improve learning outcomes for students with dyslexia. It concludes with key recommendations for inclusive practices which teachers could use to ensure students with dyslexia have the same opportunities to achieve as their peers.

\section{ANALYSIS OF THE LITERATURE}

In New Zealand, there are several organisations that offer tutoring to students outside of the school environment. SPELD NZ is one such organisation. Waldie, Austin, Hattie and Fairbrass (2014) conducted a study which investigated "the efficacy of SPELD NZ's specialist intervention" (p. 22) in which SPELD NZ worked alongside several schools nationwide. Forty two students took part in 60 tutoring sessions with qualified SPELD NZ teachers. The sessions, which were held in schools, during school hours, were conducted twice a week for a duration of 45 minutes. SPELD NZ's philosophy is to use assessment to develop individualised plans for each student depending on their needs (Waldie et al., 2014). Results were positive with substantial gains recorded for all 42 students, particularly in verbal comprehension and phonemic awareness. In summary, identifying the needs of individual students and designing an intensive programme which used strategies based on these needs resulted in academic gain.

Exeley (2003) investigated "whether teaching to students preferred learning styles would improve their performance and attainment in both literacy and numeracy" (p. 213). Exeley worked with a group of seven dyslexic students in 
England and identified the students' preferred learning styles with the majority identifying visual learning as their preferred option, closely followed by kinaesthetic learning. Results showed that by adjusting teaching strategies to reflect a student's preferred learning style, academic gains were made. For five students this was evident through the quantifiable results, but observations showed that the other two students developed a "fuller understanding of spelling patterns and mathematical concepts" (2003, p. 218). In summary, teaching to students' preferred learning styles resulted in improved educational outcomes.

Firth, Frydenberg and Bond (2012) and Firth, Frydenberg, Steeg and Bond (2013) evaluated the outcomes of the Success and Dyslexia programme which was introduced into two Australian primary schools with the aim of helping students to develop coping strategies (Firth et al., 2012). The programme involved two models: a whole school model in which a "universal coping program" (Firth et al., 2012, p. 149) was delivered to all year 6 students; and a learning disabilities support group to which students with learning disabilities attended in addition to the whole school approach. The 2012 report provides a summary of the beneficial effects on the students through teacher reports, interviews with teachers, school documents and surveys (Firth et al., 2013). The 2013 report provides data on the effects on students, gathered through student surveys. To summarise, the teachers and principals were positive about the effects the programme had on students and reported increased use of coping strategies by the students (Firth et al., 2012).

\section{EVALUATION OF STRATEGIES}

The Waldie et al. (2014) study on SPELD NZ showed benefits to students with dyslexia when a frequent, intensive, individualised programme of learning was delivered within the school environment. Aspects of the programme would, however, be difficult to replicate in everyday teaching practices in New Zealand schools. Firstly, the programme required the removal of the student from the class for 45 minutes, twice a week. It is unlikely that teachers would be able to spend this length of time to work with a student on a one-to-one basis. It is also important to consider whether withdrawing a student from the class for that length of time is beneficial. Students would miss out on other curriculum content and time spent interacting with their peers and it could also cause the student to feel isolated or different due to their learning difficulties. The process of withdrawing a student from class does not reflect inclusive practice and teachers could explore other, more inclusive practices, which support the student within the classroom environment.

Despite these drawbacks, Waldie et al. (2014) highlighted some benefits which teachers can reflect on. The first is that the programme is designed around areas which are a weakness for students with dyslexia, in particular, "phonological awareness, phoneme/grapheme knowledge, visual and auditory processing, processing speed and sequencing" (p. 24). This highlights the need for teachers to ensure that they focus on supporting students in these areas. The second benefit is the idea of creating individualised programmes designed on student need.

Exeley's (2003) study acknowledges the individual nature of student preferences to learning, particularly in regard to learning styles. While Waldie et al. (2014) identified what students need to learn, Exeley (2003) focused on how 
students prefer to learn. Results from Exeley's study show that by teaching according to individual preferences of learning style, (in this case, visual and kinaesthetic) students made improvements in spelling and numeracy. As only seven participants were involved in the research, the transferability of Exeley's study is, however, limited and it is difficult to make definitive statements from such a small research base. On the other hand, in support of Exeley, a similar study in the United States (Giess, Rivers, Kennedy \& Lombardino, 2012) investigated the effectiveness of the Barton Reading and Spelling system. Students were withdrawn from class to work with trained tutors who followed a prescribed programme of instruction which was based on multisensory approaches which "use visual, auditory and tactile-kinesthetic pathways to explicitly teach phonology, phonological-awareness, and sound-symbol correspondence" (p. 61). Results showed that this was an effective approach to improving students' reading skills. Based on the evidence from these two studies, teachers may find it useful to consider how their students with dyslexia prefer to learn, and to incorporate appropriate strategies to meet students' preferences.

The Universal Design for Learning framework (Meyer, Rose \& Gordon, 2014) suggests that teachers should be presenting information in multiple formats to ensure students engage in ways that are appropriate for them. For example, telling students what the task is that they are expected to complete (auditory approach) but also writing the instructions on the board and supporting the written instructions with a picture or a diagram (visual approach). Mills (2018) supports this approach suggesting that multisensory approaches will have benefits for all students in the classroom, not just those with dyslexia.

Firth et al. (2012) and Firth et al. (2013) focused on students, teaching them strategies to deal with the frustrations and challenges of being dyslexic. The learning difficulties experienced by students with dyslexia mean that they face many hurdles in the classroom. According to Tunmer and Greaney (2010) these repeated failures can lead to "negative self-perceptions of ability" (p. 231) resulting in a lack of effort by dyslexic students. The Success and Dyslexia programme evaluated by Firth et al. (2012) was used as an opportunity to address these issues and to help students to replace negative perceptions or behaviours with positive coping strategies. All students were encouraged to identify negative behaviours they exhibited when they faced a problem and were taught alternative behaviours such as positive thinking, assertiveness, and goal setting and problem solving skills. Teachers who took part in the study reported several positive effects including increased awareness of learning disabilities, increased confidence displayed by some students and a "sense of inclusion and engagement by all students" (Firth et al., 2012, p. 159). Although the study included over 100 students, 23 of whom had dyslexia, the authors claimed that follow up studies were needed with a larger sample. Building positive self-esteem and developing support systems have also been recommended by other researchers as effective strategies for students with dyslexia (Armstrong \& Squires, 2012; Karten, 2015). 


\section{IMPLICATIONS FOR FUTURE PRACTICE}

The New Zealand Curriculum (Ministry of Education, 2007) is the document which guides all teaching practice in New Zealand schools. It places the student at "the centre of teaching and learning" (p. 9), ensuring that education is inclusive of every student, no matter what their individual circumstances and needs are. Teachers need to develop effective teaching strategies to ensure students with dyslexia have the same access to learning opportunities as their peers. The literature evaluated in this research overview has highlighted several strategies that teachers can use. Waldie et al. (2014) identified the benefits of assessing the individual needs of students and creating individualised plans for each student depending on their needs, which if used in combination with Exeley's (2003) idea of teaching to a student's learning preference, could have powerful effects on student outcomes. Exeley (2003), Meyer et al. (2014) and Mills (2018) emphasised the importance of including multi-sensory approaches which give students with dyslexia a greater chance to access learning, to engage and contribute. Firth et al. (2012) and Firth et al. (2013) remind teachers that strategies do not need to centre on direct learning interventions. It is just as important to teach students key coping skills in order to build resilience and overcome challenges. 


\section{REFERENCES}

Armstrong, D., \& Squires, G. (2012). Contemporary issues in special educational needs: Considering the whole child. Maidenhead, United Kingdom: McGraw-Hill Education

Exeley, S. (2003). The effectiveness of teaching strategies for students with dyslexia based on their preferred learning styles. The British Journal of Special Education, 30(4), 213-220.

Firth, N., Frydenberg, E., \& Bond, L. (2012). An evaluation of success and dyslexia - a multi component school-based coping program for primary school students with learning disabilities: Is it feasible? Australian Journal of Learning Difficulties, 17(2), 147-162.

Firth, N., Frydenberg, E., Steeg, C. \& Bond, L. (2013). Coping successfully with dyslexia: An initial study of an inclusive school-based resilience program. Dyslexia, 19(2), 113-130.

Giess, S. A., Rivers, O. K., Kennedy K. \& Lombardino, L. J. (2012). Effects of multisensory phonics-based training on the word recognition and spelling skills of adolescents with reading disabilities. International Journal of Special Education, 21(1), 60-73.

Karten, T. (2015). Inclusion strategies that work! Thousand Oaks, CA: Corwin.

Meyer, A., Rose, D.H., \& Gordon, D. (2014). Universal design for learning: Theory and Practice. Wakefield, MA: CAST Professional Publishing.

Mills, J. R. (2018). Effective multi-sensory strategies for students with dyslexia. Kappa Delta Pi Record, 54(1), 36-40.

Ministry of Education. (2007). The New Zealand Curriculum. Wellington, New Zealand: Learning Media.

Tunmer, W., \& Greaney, K. (2010). Defining dyslexia. Journal of Learning Disabilities, 43(3), 229-243.

Waldie, K.E., Austin, J., Hattie, J.A. \& Fairbrass, M. (2014). SPELD NZ remedial intervention for dyslexia. New Zealand Journal of Educational Studies, 49 (1), 21-36. The opinions expressed are those of the paper author(s) and not the New Zealand Journal of Teachers' Work.
Copyright is held by individual authors but offprints in the published format only may be distributed freely by individuals provided that the source is fully acknowledged. [ISSN-1176-6662] 